\title{
Numerical Simulation of Consolidation Characteristics of Diluted Debris Flow
}

\author{
Danyi SHEN ${ }^{\mathrm{a}, \mathrm{b}}$, Zhenming SHI ${ }^{\mathrm{a}, \mathrm{b}}$ and Hongchao ZHENG ${ }^{\mathrm{a}, \mathrm{b}, 1}$ \\ ${ }^{a}$ Department of Geotechnical Engineering, Tongji University, Shanghai, 200092, \\ China \\ ${ }^{\mathrm{b}}$ Ministry of Education Key Laboratory of Geotechnical and Underground Engineering, \\ Tongji University, Shanghai, 200092, China
}

\begin{abstract}
The consolidation settlement of diluted debris flow is a complicated process of solid-liquid two-phase flow deposition. In this paper, the consolidation and settlement characteristics of uniform-graded and wide-graded debris flow materials in clear water and slurry are simulated by using this method. The results show that in the process of consolidation, sorting occurs in the top and middle position of uniform-graded materials at low concentration, while the middle particles are separated in reverse direction at high concentration. The middle particles of wide-graded material are hardly separated in the whole consolidation process. The velocity of dissipation of excess pore water pressure in the clean water is faster than that of slurry, and the dissipation time of wide-graded materials is longer than that of uniform-graded materials. The research results are helpful to reveal the mechanism of consolidation settlement of diluted debris flow in mesoscale.
\end{abstract}

Keywords. CFD-DEM model, debris flow, consolidation settlement, excess porewater pressure

\section{Introduction}

Diluted debris flow is a common geological disaster all over the world, which has caused great losses to people's lives and property [1]. Consolidation and accumulation of diluted debris flow is a complex sedimentary process of solid - liquid two-phase flow. Beris et al. [2] analyzed the settling characteristics of single particles in Bingham fluid and found that the particles would be in suspension when the yield stress larger than 0.14. Major [3] described the consolidation process of debris flow by using onedimensional consolidation theory, found that the permeability coefficient increases with the decrease of slurry content, and deposition phenomenon was caused at high concentration. Chen et al. [4] established a consolidation equation to described the consolidation time, settlement size, dissipation of pore pressure and consolidation degree of debris flow.

Studies on consolidation and accumulation mechanism of debris flow, especially on consolidation characteristics of different types of diluted debris flow are limited. This study analyzes the self-weight consolidation of diluted debris flow based on CFD-

\footnotetext{
${ }^{1}$ Hongchao Zheng, Department of Geotechnical Engineering, Tongji University, Shanghai, 200092, China; E-mail: 908799751@qq.com.
} 
DEM method, aiming to reveal the settlement and consolidation mechanism from the meso-scale. The results can provide reference for the analysis of diluted debris flow.

\section{Introduction of CFD-DEM Model}

The CFD-DEM model consists of DEM module and CFD module. The solid particles in DEM module is controlled by Newton equation, and shear fluid in CFD module is controlled by Navier-Stokes equation [5-6]. The DEM module and CFD module are solved by mutual iteration (figure 1). The DEM module provides the velocity and position information of each particle, thus the corresponding porosity ( $n$ ) can be obtained. The interaction force (fint) between shear fluid and particles is calculated by empirical regression equations, and both the porosity and the interaction force are transferred to the CFD module. The flow velocity and pressure gradient are solved by sim-PLE algorithm.

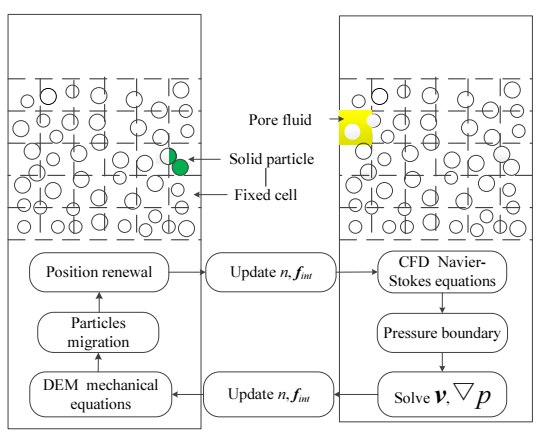

Figure 1. Coupling framework of CFD-DEM model.

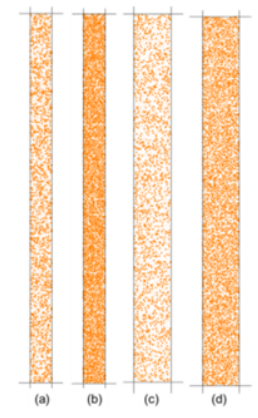

Figure 2. Sample models: (a) $\mathrm{U}_{1} ;\left(\right.$ b) $\mathrm{U}_{2} ;\left(\right.$ c) $\mathrm{W}_{1}$; (d) $\mathrm{W}_{2}$.

\subsection{Governing Equations for Solid Particles}

The solid particle is governed by Newton's second law. Considering particles in the flow field grid are controlled by gravity $f_{\mathrm{g}}$, drag force $f_{\mathrm{d}}$, buoyancy $f_{\mathrm{b}}$ and contact force $f_{\mathrm{c}}$ of adjacent particles, Newton's equation for a single particle is:

$$
m \frac{d v}{d t}=\left(f_{\mathrm{g}}+f_{\mathrm{d}}+f_{\mathrm{b}}+f_{\mathrm{c}}\right)
$$

Where $m, v$ are the mass and velocity of particle, $t$ is the time, $f_{\mathrm{g}}, f_{\mathrm{b}}$ and $\boldsymbol{f}_{\mathrm{c}}$ are expressed as follow,

$$
\left\{\begin{array}{l}
\boldsymbol{f}_{\mathrm{g}}=\rho_{\mathrm{s}} V_{\mathrm{p}} \boldsymbol{g} \\
\boldsymbol{f}_{\mathrm{b}}=\rho_{\mathrm{f}} V_{\mathrm{p}} \boldsymbol{g} \\
\boldsymbol{f}_{\mathrm{c}}=\boldsymbol{K} \boldsymbol{U}
\end{array}\right.
$$


Where $\rho_{\mathrm{s}}$ and $\rho_{\mathrm{f}}$ are the densities of bed particles and viscous fluid, $\boldsymbol{g}$ is the gravitational acceleration, $V_{\mathrm{p}}$ is the particles volume, $\boldsymbol{K}$ is the contact stiffness, $\boldsymbol{U}$ is the overlapping displacement of adjacent particles.

\subsection{Interaction Force between Fluid and Solid}

The drag force $\boldsymbol{f}_{\mathrm{d}}$ includes the interaction force $\boldsymbol{f}_{\text {int }}$ and the pressure gradient $\nabla p$,

$$
\boldsymbol{f}_{\mathrm{d}}=\left(\frac{\boldsymbol{f}_{\text {int }}}{1-n}+\nabla p\right) V_{\mathrm{s}}
$$

The porosity $n$ can be obtained by the following equation:

$$
n=1-\frac{V_{\mathrm{s}}}{V_{\mathrm{e}}}
$$

Where $V_{\mathrm{s}}$ and $V_{\mathrm{e}}$ are volumes of solid particles and fluid grids. For particles in two or more fluid grids, only considering the volume $V_{\mathrm{s}}$ of green part in figure 1 . For a passive flow, $\nabla p$ is generated by the interaction between the fluid and the particles.

$$
\nabla p=\frac{f_{\text {int }}}{n}
$$

The $f_{\text {int }}$ is calculated by the equation proposed by Tsuji [6],

$$
f_{\text {int }}=\beta\left(u-\overline{v_{\mathrm{p}}}\right)
$$

Where $\left(\boldsymbol{u}-\overline{v_{\mathrm{p}}}\right)$ is the relative velocity of shear fluid and particles, $\beta$ is the empirical interaction coefficient,

$$
\beta=150 \frac{(1-n)^{2}}{\bar{d}^{2} n} \eta+1.75 \frac{(1-n)}{\bar{d}} \rho_{\mathrm{f}}|\boldsymbol{u}-\bar{v}|
$$

Where $\bar{d}$ is the average particle size, $\eta$ is the viscosity coefficient of the shear fluid.

\subsection{Governing Equations for Shear Fluids}

The governing equation of the CFD module is the Navier-Stokes equation, including the mass conservation equation and the momentum conservation equation, 


$$
\begin{gathered}
\frac{\partial n}{\partial t}=-(\nabla \cdot n \boldsymbol{u}) \\
\frac{\partial(n \boldsymbol{u})}{\partial t}=-(\nabla \cdot n \boldsymbol{u} \boldsymbol{u})-\frac{n}{\rho_{\mathrm{f}}} \nabla p-\frac{n}{\rho_{\mathrm{f}}} \nabla \cdot \boldsymbol{\tau}+n \boldsymbol{g}+\frac{\boldsymbol{f}_{\text {int }}}{\rho_{\mathrm{f}}}
\end{gathered}
$$

Where $\tau$ is the viscous shear stress of the shear fluid, the Newtonian fluid model is adopted when the shear fluid is a clean flow, and the Bingham constitutive model is adopted when the shear fluid is a slurry flow.

\section{Consolidation Characteristics of Debris Flow}

\subsection{Numerical Simulation Scheme}

Two kinds of grain composition materials are used to study the gravity consolidation characteristics of debris flow. One is uniform-graded material, the ratio of particle size of $0.75 \mathrm{~mm}$ and $1.5 \mathrm{~mm}$ are 0.4 and 0.6 . The other is wide-graded material, the ratio of particle size of $0.75 \mathrm{~mm}, 1.5 \mathrm{~mm}$ and $2.5 \mathrm{~mm}$ are $0.25,0.375$ and 0.375 , respectively. The viscosity coefficient of clean water is $0.001 \mathrm{~Pa} \cdot \mathrm{s}$, and that of slurry are 0.008 and $0.01 \mathrm{~Pa} \cdot \mathrm{s}$. The consolidation experiments of 4 samples in 2 kinds of slurry are carried out (table 1).

The establishment of numerical modeling can be divided into three steps:

- Wall generation: the height of wall is $0.5 \mathrm{~m}$, the width is set to 20 times the maximum particle size, that is, the width for uniform-graded and wide-graded are $30 \mathrm{~mm}$ and $50 \mathrm{~mm}$.

- Particle generation: particles are uniformly generated in 10 layers with concentrations of 0.2 and 0.4 . The uniform-graded and wide-graded materials with concentrations of 0.2 and 0.4 are numbered $U_{1}$ and $U_{2}$, and $W_{1}$ and $W_{2}$.

- Flow field generation: the top side is drainage boundary, and other side are non-drainage boundaries. The flow field is divided into a grid of fluid cells with a width and height of $4 \times 60$ (figure 2 ).

Table 1. Numerical simulation conditions

\begin{tabular}{llllll}
\hline Condition & Sample & $\begin{array}{l}\text { Particle } \\
\text { concentration }\end{array}$ & Fluid & $\begin{array}{l}\text { Density } \\
\left(\mathbf{k g} / \mathbf{m}^{\mathbf{3}}\right)\end{array}$ & $\begin{array}{l}\text { Coefficient of viscosity } \\
(\mathbf{P a} \cdot \mathbf{s})\end{array}$ \\
\hline $\mathrm{C}_{1}$ & $\mathrm{U}_{1}$ & 0.2 & clean water & 1000 & 0.001 \\
$\mathrm{C}_{2}$ & $\mathrm{U}_{2}$ & 0.4 & clean water & 1000 & 0.001 \\
$\mathrm{C}_{3}$ & $\mathrm{~W}_{1}$ & 0.2 & clean water & 1000 & 0.001 \\
$\mathrm{C}_{4}$ & $\mathrm{~W}_{2}$ & 0.4 & clean water & 1000 & 0.001 \\
$\mathrm{C}_{5}$ & $\mathrm{U}_{1}$ & 0.2 & slurry & 1206 & 0.008 \\
$\mathrm{C}_{6}$ & $\mathrm{U}_{2}$ & 0.4 & slurry & 1280 & 0.01 \\
$\mathrm{C}_{7}$ & $\mathrm{~W}_{1}$ & 0.2 & slurry & 1206 & 0.008 \\
$\mathrm{C}_{8}$ & $\mathrm{~W}_{2}$ & 0.4 & slurry & 1280 & 0.01 \\
\hline
\end{tabular}




\subsection{Results}

\subsubsection{Analysis of Particles Settlement}

The settlement process under the condition of clean water is shown in figure 3 . The particles deposit from bottom to top, and the deposition thickness increases. For $\mathrm{C}_{1}$, the particles are evenly distributed at the initial stage, then as the settlement process progresses, some particles are clustered together, the distribution of particles is not uniform. For $\mathrm{C}_{2}$, the particles change little and is almost evenly distributed. For $\mathrm{C}_{3}$ and $\mathrm{C}_{4}$, It can be found that turbulent flow has a more significant effect on wide-graded materials compared with uniform-graded. This is mainly because the drag force has more significant effect on fine particles $(0.75 \mathrm{~mm})$.

The change of volume concentration under clean water is shown in figure 4. Particles deposit from bottom to top, and the volume concentration at the bottom increases rapidly to the maximum volume concentration $(0.64)$. For $\mathrm{C}_{1}$, the volume concentration is around 0.2 at the initial stage. Then, the volume concentration of sediment at the bottom is close to the maximum value, and the interface of maximum volume concentration moves upward with the development of settlement. The volume concentration in $C_{2}$ is larger than $C_{1}$, but the maximum value after stable settlement is the almost same. This is because the bulk concentration of particles depends on how the particles are arranged not the deformation of particles. The change of the volume concentration of $\mathrm{C}_{3}$ and $\mathrm{C}_{4}$ is similar to that of $\mathrm{C}_{1}$ and $\mathrm{C}_{2}$. The difference is that the maximum volume concentration (0.72) of the wide-graded material is higher than that of the uniform-graded material. The reason is that the small particles of wide-graded material $(0.75 \mathrm{~mm})$ fill the gap of large particles $(2.5 \mathrm{~mm}$ and $1.5 \mathrm{~mm})$, resulting in small void ratio.

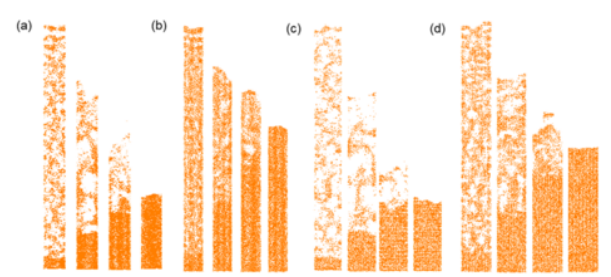

Figure 3. The settlement process of particle at different times under the condition of clean water: $(a) \mathrm{C}_{1}$; (b) $\mathrm{C}_{2} ;(\mathrm{c}) \mathrm{C}_{3} ;(\mathrm{d}) \mathrm{C}_{4}$.

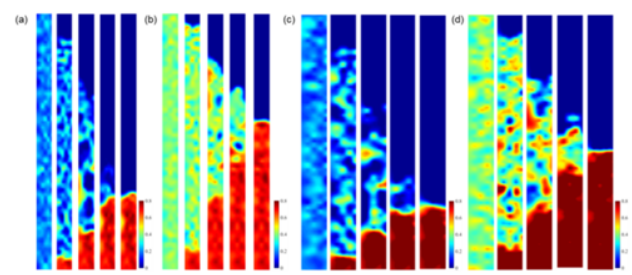

Figure 4. Volume concentration at different times under clean water condition: $(a) \mathrm{C}_{1} ;(\mathrm{b}) \mathrm{C}_{2} ;(\mathrm{c}) \mathrm{C}_{3} ;(\mathrm{d}) \mathrm{C}_{4}$.

Particles is sorted in the process of settling (figure 5). For $\mathrm{C}_{1}$, particle sorting first occurs at top area, the proportion of small particles of $0.75 \mathrm{~mm}$ increases, while that of large particles of $1.5 \mathrm{~mm}$ decreases. This is because the settlement velocity of large particles is larger than that of small particles. Besides, the proportion of large particles is 
reduced at middle area, while no sorting occurs at bottom area. For $\mathrm{C}_{2}$, particles in the top region are sorted, but sorting degree is weaker than that in $\mathrm{C}_{1}$. The reason may be that the collision effect between particles is strengthened at high particle concentration, and the sorting path of particles is inhibited. For wide-graded materials $\left(\mathrm{C}_{3}, \mathrm{C}_{4}\right)$, the large particles and small particles are sorted, while medium particles are not sorted. Besides, the sorting law of uniform-graded materials and wide-graded materials in slurry is similar to that in clean water.

\subsubsection{Analysis of Excess Pore Fluid Pressure}

Dissipation of excess pore fluid pressure (EP) under different conditions is shown in figure 6. For $\mathrm{C}_{1}$, dissipation of $\mathrm{EP}$ decreases linearly at different depths from top to bottom. The maximum EP is $1600 \mathrm{~Pa}$ and the dissipation time is $4.5 \mathrm{~s}$. The volume concentration and the EP is higher in condition 2, and the EP reaches $3200 \mathrm{~Pa}$. However, the dissipation time of $\mathrm{C}_{1}$ and $\mathrm{C}_{2}$ are almost the same due to the viscosity coefficient is small (0.001) and dissipation is fast in clean water. The dissipation of EP is linear at the top and bottom, but has a turning point in the middle position of $\mathrm{C}_{2}$. This phenomenon is mainly caused by the difference of EP between the upper and lower positions in the process of particle consolidation. For $\mathrm{C}_{3}$, the dissipation time is $5 \mathrm{~s}$, slightly longer than that of $\mathrm{C}_{1}$. The reason may be that the void ratio of the wide-graded material is smaller than that of the uniform-graded material after settlement, and EP dissipation rate is much smaller. This difference in particle composition can also explain the difference in dissipation time between $\mathrm{C}_{2}$ and $\mathrm{C}_{4}$.

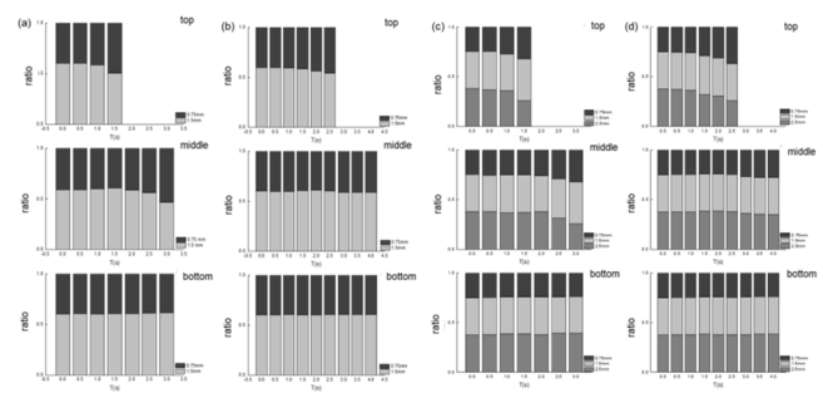

Figure 5. Particles sedimentation and separation under clean water condition: $(a) C_{1} ;(b) C_{2} ;(c) C_{3} ;(d) C_{4}$.
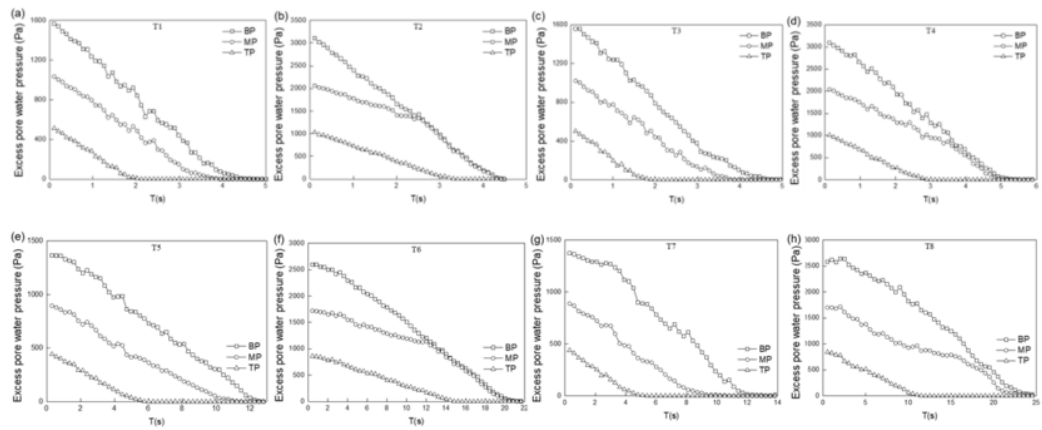

Figure 6. Dissipation of excess pore fluid pressure under different conditions: (a), (b), (c), (d), (e), (f), (g) and $(h)$ are conditions of $\mathrm{C}_{1} \sim \mathrm{C}_{8}$. Note: BP is the bottom, MP is the middle, and TP is the top 
The dissipation time of $\mathrm{C}_{5}$ is $12 \mathrm{~s}$, much longer than that of $\mathrm{C}_{1}$. The main reason is that the viscosity coefficient of $\mathrm{C}_{5}$ is 0.008 , and the dissipation rate of $\mathrm{EP}$ is low. The continuous EP prevents the sedimentation of particles, while the position height of particles conversely inhibits the dissipation of EP. The dissipation time of condition 6 is up to $21 \mathrm{~s}$. The reason may be due to the larger particle concentration and the high EP (with a peak of $2600 \mathrm{~Pa}$ ). The dissipation rate of excess pore fluid pressure is small. In addition, the dissipation law of $\mathrm{C}_{7}$ and $\mathrm{C}_{8}$ is the same as that of $\mathrm{C}_{3}$ and $\mathrm{C}_{4}$.

\section{Conclusion}

In this paper, the CFD-DEM coupling method is used to analyze the consolidation settlement of uniform-graded materials and wide-graded materials under clear water flow and slurry conditions. The main conclusions are as follows:

(1) The coupling of CFD-DEM model can effectively simulate particle displacement and pore pressure dissipation during consolidation process from a mesoscopic perspective.

(2) The particles sorting occurs at top and middle area, and almost no sorting occurs at the bottom are of uniform-graded materials at low concentration, while the middle particles are separated in reverse direction at high concentration, but the middle particles of wide-graded material are hardly separated in the whole process.

(3) Under the condition of clean water, the dissipation rate of excess pore fluid pressure is fast. The dissipation time of uniform-graded and wide-graded materials at low concentration is $4.5 \mathrm{~s}$, and at high concentration are $4.5 \mathrm{~s}$ and $5 \mathrm{~s}$. Under slurry conditions, the dissipation rate of excess pore fluid pressure is slow. The dissipation time of uniform-graded and wide-graded materials at low concentration is $12 \mathrm{~s}$, and at high concentration are $20 \mathrm{~s}$ and $24 \mathrm{~s}$.

\section{Acknowledgement}

This project was supported by School-Enterprise-Cooperation Project (2020-K-030).

\section{References}

[1] Hampton MA. Buoyancy in debris flows. Journal of Sedimentary Research. 1979 Sep; 49(3): 753-758.

[2] Beris AN, Tsamopoulos JA, Armstrong RC, Brown RA. Creeping motion of a sphere through a Bingham plastic. Journal of Fluid Mechanics. 1985 Sep; 158(1): 219-244.

[3] Major JJ. Gravity-driven consolidation of granular slurries: implications for debris-flow deposition and deposit characteristics. Journal of Sedimentary Research. 2000 Jan; 70(1):64-83.

[4] Chen HK, He XY, Zhong Y, Tang HM. Study on consolidation mechanism of debris Flow deposit. Advanced Materials Research. 2012 Jan; 446(449):1674-1684.

[5] Anderson TB, Jackson R. Fluid mechanical description of fluidized beds, Equations of motion. Industrial and Engineering Chemistry Fundamentals. 1967 Nov; 6(4): 527-539.

[6] Tsuji Y, Kawaguchi T, Tanaka T. Discrete particle simulation of two-dimensional fluidized bed. Powder Technology. 1993 Oct; 77(1): 79-87. 